\title{
Employers' Perceptions of the Labour Contract Law: Regulatory Responses in the Small and Medium-Sized Enterprise Sector in China
}

DOI:

10.1108/PR-04-2020-0300

\section{Document Version}

Accepted author manuscript

Link to publication record in Manchester Research Explorer

Citation for published version (APA):

Li, S., \& Rees, C. (2021). Employers' Perceptions of the Labour Contract Law: Regulatory Responses in the Small and Medium-Sized Enterprise Sector in China. Personnel Review, 50(3), 1056-1072. https://doi.org/10.1108/PR04-2020-0300

\section{Published in:}

Personnel Review

\section{Citing this paper}

Please note that where the full-text provided on Manchester Research Explorer is the Author Accepted Manuscript or Proof version this may differ from the final Published version. If citing, it is advised that you check and use the publisher's definitive version.

\section{General rights}

Copyright and moral rights for the publications made accessible in the Research Explorer are retained by the authors and/or other copyright owners and it is a condition of accessing publications that users recognise and abide by the legal requirements associated with these rights.

\section{Takedown policy}

If you believe that this document breaches copyright please refer to the University of Manchester's Takedown Procedures [http://man.ac.uk/04Y6Bo] or contact uml.scholarlycommunications@manchester.ac.uk providing relevant details, so we can investigate your claim.

\section{OPEN ACCESS}


Employers' Perceptions of the Labour Contract Law: Regulatory Responses in the Small and Medium-Sized Enterprise Sector in China

\begin{tabular}{|r|l|}
\hline Journal: & Personnel Review \\
\hline Manuscript ID & PR-04-2020-0300.R1 \\
\hline Manuscript Type: & Research Article \\
\hline Keywords: & Employment relations, SMEs, Institutional theory, HRM practices, the LCL \\
\hline Methodologies: & Qualitative \\
\hline
\end{tabular}




\title{
Employers' Perceptions of the Labour Contract Law: Regulatory Responses in the Small and Medium-Sized Enterprise Sector in China
}

\begin{abstract}
Purpose - The purpose of this paper is to explore employers' perceptions of China's Labour Contract Law (LCL) and its influence on employment relations and human resource management (HRM) practices in small and medium-sized enterprises (SMEs). Design/methodology/approach - This paper adopts a qualitative approach based on 24 interviews with owners and HR managers in 23 privately-owned SMEs in eastern and western China.

Findings - Mixed levels of reported compliance with the provisions of the LCL legislation indicate that the regulatory adoptive behaviours of SME employers are partially explained by the coercive mechanism. Various strategies adopted by employers suggest that when under the pressure of law, SMEs are formalising their employment practices while simultaneously seeking to maintain a degree of informality in respect these practices.

Research limitations/implications - The adopted qualitative approach may limit the findings to be explorative within broader national contexts.

Practical implications - The move towards more formalised practices helps to address issues such as high turnover and widespread labour shortage in SMEs. The paper is likely to be of interest to policymakers seeking to gain insights into employers' perceptions as a means to develop more effective labour regulations.

Originality/value - Unlike most of existing literature examining the general compliance to the LCL and workers' perspectives, this paper reports the views of SME employers; as such it offers an original contribution to understanding of the role and behaviours of SME employers in regulatory responses in the studied context.

Keywords - Employment relations, SMEs, Institutional theory, HRM practices, the LCL

Paper type Research paper
\end{abstract}

\section{Introduction}

Since the 1980s, employment relations in China have been shifting from a planned centralised system, characterised by life-long employment and cradle-to-grave welfare, to a more market-oriented approach characterised by greater employer autonomy in employment decisions (Cooke, 2012; Freeman and Li, 2013). This shift has enabled organisations to improve their efficiency but has also created tensions due to the imbalance of power between employers and employees. In recognition of these growing tensions and the disputes arising from them, the Labour Contract Law (LCL) was enacted in 2008 to address the labour issues which were arising on an increasingly frequent basis in the private sector (Cooke, 2012; Pringle and Meng, 2018).

Despite its enactment in 2008, relatively little is known about how the LCL has impacted on employment relations and human resource management (HRM) especially in the SME sector (Sheldon and Sanders, 2016; Shen, 2010). The extant but limited research into the 
implementation of the LCL has tended to investigate the effectiveness of the law by placing an emphasis on workers' interests, rights and wellbeing, especially those of migrant workers (see Freeman and Li, 2013; Gao et al., 2017; Yang, 2020). Empirical evidence relating to the impact of the LCL remains scarce especially when considering this topic from employers' perspectives. This gap in knowledge needs to be addressed in order to gauge the extent of the differences between the desired outcomes of the regulatory framework from a regulator's perspective and SMEs' regulatory responses; as Mayson and Barrett (2017: 193) state: "firm responses are largely driven by how the owner-manager thinks (or interprets) employment relations should be rather than what the regulators intended". Further, in noting the limitations of existent research, Cui et al. (2013) highlight that the impact of the LCL on improving employee benefits varies substantially across firms of differing sizes, ownership, sectors and regions. Similarly, while not explicitly including the SME sector in their analysis, Lan et al. (2015: 289), conclude that rates of implementation of the LCL: “... vary across and within regions and sectors, among workers in the same industries and sometimes in the same workplaces, and different articles of the law are implemented to differing degrees in different sectors". As such, the findings of previous research provides a strong rationale for examining the impact of the LCL within the SME sector particularly given the importance of this sector to the economy in China.

In order to address this gap, this study explores the influence of the LCL on employment relations and HRM practices in SMEs in China by examining how SME owners and HR managers have responded to this legislation. It is anticipated that the findings will be of interest to various actors operating at both policy and practitioner levels in this national context.

\section{Theories on firms' regulatory responses}

Institutional theory suggests that organisations need to comply with a set of institutional forces for the purpose of obtaining legitimacy to perform and survive. According to the theory, firms operating under similar institutional settings tend to converge in terms of practices, structures, even behaviours. In pursuing this line of reasoning, Paauwe and Boselie (2003: 61) highlight three mechanisms which offer causal explanations for this homogeneity. Specially, the "coercive" mechanism indicates that laws, legislations, regulations, standards of labour unions can exert an impact on firms' adoption. In our view, given the history of labour relations and governance practices in the research context we are exploring, the 
"coercive" mechanism is intuitively relevant and may have the potential to offer insights into the role of labour regulations in shaping SMEs' practices in China.

Institutional theory research into the issue of firm size and the adoption of regulatory management practices is relatively scarce and has, perhaps, been neglected especially in relation to small firms (see Edwards et al., 2006). This has led to speculation as to whether, for example: “... different pressures may influence organizations of differing sizes - whereas regulatory and market pressures may influence larger organizations, smaller organizations may be more influenced by competitive pressures" (Zhu and Sarkis, 2007: 4353). Uncertainty of this nature presents further rationale for research which examines, from an institutional theory perspective, the influence of internal organisational dynamics and the role of stakeholders' on regulatory adoption practices within organisations of different sizes. In this study, we seek to contribute to the debate by focusing on the SME sector.

Despite the neglect of the SME sector and the lack of theory building in this field, a number of scholars have made contributions when theorising how SMEs are influenced by regulations. For example, Mayson and Barrett (2017) brought the concepts of embedddness and sensemaking together to explain small firms' regulatory responses. Their approach highlights that heterogeneous responses made by owner-managers are dependent upon how they make sense of the internal and external situatedness. Further, these responses in turn shape the contexts in which firms operate; thus, the relationship between institutional settings and human agency can be interpreted as an ongoing process of interactions. Malesky and Taussig (2017) emphasise that influential aspects of these interactions, particularly involving large firms and governments, may even take place during the design stage of regulations. In another contribution based on a processual view, Mallett et al. (2019) identified and conceptualised four interconnected processes: identification-interpretation; strategisation; negotiation; and adaptation. Their framework provides insights into how regulations affect SMEs. Both of these theoretical approaches are highly relevant to this study as they emphasise the role of human actors and exchanges between environments and human actors within the SME sector.

In seeking to explore ways in which regulations affect SMEs, the current study is theoretically informed by drawing upon and integrating concepts involving institutional forces, the role of human actors and four key processes. Given that various employment regulations could potentially affect SMEs, it is not intended to address this issue in general. Instead, a more focused approach is adopted by identifying the Labour Contract Law (LCL) as a specific institutional force in China. The human actors are SME employers as they exert 
considerable influence on firms' strategies and decisions; their perceptions and subsequent adjustments of HRM practices in their organisations, offer insights into the interpretation and adaption of the LCL from employers' perspectives.

\section{Employment relations and HRM in SMEs in China}

In China, the legal recognition of the private economy has empowered employers to make employment decisions and select HRM practices which are conducive to their businesses (Liang et al., 2012; Li et al., 2019; Xiu et al., 2017). As a corollary of this increasing level of managerial discretion, owners of private enterprises (PEs) tended to take advantage of informal employment practices to minimise labour costs and to maximise flexibility of labour by eschewing employment regulations such as the creation of labour contracts (Cooke, 2011, 2012). Correspondingly, while the private sector expanded, there was a growing awareness among employees of their legal rights at work leading to increased tensions between employers and employees (Frenkel and Yu, 2015).

Although there is emergent evidence to indicate that some SMEs are adopting advanced HRM practices to cope with emerging challenges in the transitional China (Harney and Alkhalaf, 2020; Newman and Sheikh, 2014), a broader body of existent literature which suggests that, prior to the enactment of the LCL, most HRM practices in SMEs in China were flexible, personalised, emergent, short-term focused, heterogeneous, and even contradictory (Cooke, 2012; Cunningham, 2010; Paul et al., 2017; Richbell et al. 2010; Singh and Vohra, 2009). Empirical evidence of this nature reveals that, in the SME context in China, HR policies and procedures were largely word of mouth and tacit with limited accompanying documentation. Informal and paternalistic HR practices relating to activities such as compensation and performance appraisal became associated with both the flexible and shortterm nature of SMEs and also the strong personal relationships prevalent in Chinese society (Kim and Gao, 2010). For example, recruitment, especially in relatively small SMEs, was reliant on convenient and low-cost sources such as referrals and family ties while selection was based on relatively unstructured methodologies (Kopnina, 2005); training and development activities tended to be under resourced mainly due to owners' concerns relating to return on investment and potential job hopping (Bai et al., 2017); performance management often involved unclear criteria of performance at the individual level and ambiguous linkage with rewards in favour of approaches to reward management which emphasised seniority and loyalty (Cunningham, 2010). Employee relations practices, in 
particularly relating to the regulation of labour relations were predominantly informal (Cooke, 2010).

This informality was, at its extreme, reflected in the form of non-existent labour contracts, the non-provision of social insurance, unfair dismissals with no compensation, excessive working hours, underpayment or non-payment of wages, poor working conditions and limited work protection (Cooke, 2012; Shen, 2010). In essence, prior to the enactment of LCL, the employment relationship in SMEs was typically temporary or short-term (Wang et al., 2009). Further, Cui et al. (2013) documented different approaches to non-compliance which SME owners were using to avoid legal obligations; these approaches included the use of short-term contracts, blank contracts, and the practice of requiring individual employees to sign two contracts with different salary rates.

\section{The LCL}

The LCL has made at least three significant changes to employment relations in China. First, the introduction of non-fixed-term labour contracts (NFTLCs) tends to be described as the most controversial change (Cooke, 2012; Freeman and Li, 2013). The LCL stipulates that, if an employee has been working for ten years consecutively or has completed two short-term contracts, the employer shall conclude a NFTLC with the employee (Article 14, see PRC, 2013). NFTLCs enhance job security for workers; they also arouse massive controversy as to whether these contracts represent a return to the "iron rice bowl" and "job for life" era resulting in high costs for employers when they terminate employment contracts (Cooke, 2012: 168; Freeman and Li, 2013; Gallagher et al., 2015; Liang et al., 2012). For example, Wang et al. (2019: 115) refer to: “... the widespread misconceptions among employers that pressure for continuing contracts brings the (disguised) return of the 'iron rice bowl' of the planned economy era, undermining their 'efficiency' logic'. However, empirical evidence regarding the impact of NFTLCs in the SME sector is extremely limited as extant literature tends to be more concerned with general compliance with the law and lacks specific reference to the SME context.

A second important aspect of the LCL is the specific requirement placed on employers to recognise formally employment relationships by means of written labour contracts (Article 10, see PRC, 2013). Recent studies have provided some empirical evidence regarding employers' use of written contracts. Gallagher et al. (2015) report a notable increase in the use of written contracts, especially for migrant workers. A similar observation is made by Freeman and $\mathrm{Li}$ (2013) who further found that the workers who had a written contract tended 
to be provided with social insurance and were less likely to suffer from wage arrears. Additionally, employees in smaller PEs were found less likely to have contracts than those in larger PEs and SOEs (ibid, 2013; Yang, 2020). This emerging evidence provides some indication that the LCL does indeed encourage formal labour contracts and further reveals the positive association between having a contract and the provision of social insurance.

Third, the LCL mandates that employees are entitled to receive severance pay and social insurance. Double severance pay is needed if unfair dismissal occurs (Article 46, 47, 87, see PRC, 2013). However, the level of severance pay and wider provision of social welfare again caused concerns among employers about increases in labour costs and decreasing demand for labour arising from the provision of the LCL. For example, Chan (2012: 24) notes that, "labour costs did increase for small and medium-size labour intensive business in low-end enterprises". Tang and Tang (2012) estimated that approximately one fifth of SMEs relying on narrow profit margins would go bankrupt or need to relocate to regions with lower labour costs if they adhered to these LCL requirements. Similarly, Gallagher et al. (2015) reported that nearly 80 per cent of the managers they surveyed anticipated increased labour costs arising from the LCL.

Although there is some empirical research which has investigated the impact of the LCL, most of this research is concerned with employee outcomes, such as the signing rates of written contracts, employee benefits, working hours, social insurance, wages, and subjective wellbeing (Cheng et al., 2015; Cui et al., 2013; Freeman and Li; 2013; Gallagher et al., 2015). Notably, reports of employers' views of the LCL are rare. Another under-explored issue relates to the enforcement and impact of NFTLCs (Freeman and Li, 2013). Despite evidence indicating that large firms and SOEs tend to comply with the LCL more readily than small businesses and PEs (Cui et al., 2013; Freeman and Li, 2013; Gallagher et al., 2015; Yang, 2020), there remains a gap of knowledge on what is happening within the SME sector. More specifically, little is known about SME owners' perspectives on the LCL; further, its influence on employment and HRM practices is under-explored in this sector.

In summary, given that SMEs in the private sector have, traditionally, been reliant on the flexibility associated with informal employment relations, the provisions of the LCL present substantial challenges for employers in this sector. The findings of the literature review and the dearth of research relating to the impact of the LCL, give rise to two research questions which are addressed in subsequent sections of the paper: first, how do SME owners and HR managers perceive the LCL?; second, how are employment and HRM practices in the SME sector influenced by the LCL? 


\section{Methodology}

This study adopts a qualitative approach, based on semi-structured interviews with 24 SMEs owners and HR managers. This approach enables the researchers to expose in depth the employers' views regarding the LCL and its influence on HRM practices (Mallett et al., 2019). The approach has been employed in previous studies of Chinese management, SMEs, labour relations and effects of regulations (Chung, 2015; Cooke and Saini, 2012; Li et al., 2016; Smith and Chan, 2015).

The data were collected from 23 SMEs in Jiangsu and Shaanxi provinces in eastern and western China. In view of the relationship-based nature of Chinese society and the sensitivity of the topic, accessibility needed to be considered when selecting sources for the research. Potential SMEs were contacted through the researchers' established social network and further SMEs were recommended by these initial contacts. Four criteria were followed for the selection of SMEs, that is, the targeted SMEs are urban-based, privately owned, have less than 300 employees (PRC, 2011), and have operational histories of more than three years. Micro, small and medium enterprises are defined respectively with employees between 1-9, 10-99 and 100-299 (ibid, 2011). Of the 23 SMEs, 11 were located in Jiangsu and 12 were located in Shaanxi province. Eight were in the manufacturing sector (for example, photovoltaic, chemical, and precise instrument manufacturing) and 15 were in the service sector (for example, real estate, education, software, and business services). Regarding the scale, ten were medium-sized, 11 were small-sized and two were micro-sized enterprises. The average size by the number of employees was 104 . The inclusion in the study of SMEs from a range of sizes was undertaken in order to permit exploration of whether regulatory responses may be linked to the relative size of SMEs. An HR department or a joint administration and HR department was present in 19 out of the 23 enterprises.

A total of 24 SME owners and HR managers were interviewed. Given that owners and HR managers are the decision makers in employment and HRM issues in organisations, they were viewed as the key potential respondents who would be in an informed position to reflect on how the firms are impacted by the LCL. The decision to interview an owner or an HR manager was made solely on the basis of availability. Of the 24 interviewees, nine were owners and 15 were HR managers. The interviews were conducted face to face on an individual basis in Mandarin lasting between one to two hours. With the consent of participants, the interviews were audio-recorded. Participants were asked about the employment practices used in their firms, their understanding of the LCL, its perceived 
influence, the adjustments and changes that had been taken on employment and HRM practices as responses to the law. An example question was: "What is your understanding of non-fixed-term labour contracts?"

The interview data were transcribed and translated from Chinese into English. Back translation was applied to interview questions and samples of the transcriptions to ensure translation equivalence. A thematic analysis approach and a recommended five-phase procedure were adopted to ensure a systematic and logical analysis of the data (Chambliss and Schutt, 2010; Cooke and Saini, 2012; Grbich, 2013). Categorisation and coding was conducted in a hierarchical manner. Guided by the main research questions, the original data were first categorised into two themes and then coded against 'attitude' and 'influence'. The 'Attitude' category was broken down into two sub-segments and coded against 'general understanding' and 'NFTLCs'. The 'Influence' category was rearranged into two subsegments and coded against 'employment' and 'HRM practices'. Contrasts and comparisons were then made; trends and patterns were observed among the codes, in order to reach our key findings.

\section{Findings}

The adopted employment practices in the SMEs are presented below as they set the scene for understanding the owners' perceptions regarding the LCL. Written contracts were used in 22 out of 23 SMEs and only one micro firm made use of alternative oral agreements. The terms of the labour contracts varied from one to five years with one year and three year contracts being the two most commonly reported lengths of contract. 15 SMEs adopted consistent contract practices throughout their workforces. In relation to size, one of the15 SMEs in this sub-group of the sample was micro, nine were small and five were medium SMEs. In relation to sector, three of the sub-group of 15 were manufacturing firms and 12 were service firms. In total, ten out of 15 were micro and small SMEs operating in the service sector. The remaining seven SMEs applied differential practices mainly based on three factors, that is, the type of employee, the seniority of the employee and the number of times the contract had been subject to renewal. Four out of this sub-group of seven were medium size SMEs in the manufacturing sector. In essence, employment contracts covering relatively lengthy periods of time tended to be issued to valued employees of relatively high rank whose employment contracts had been renewed on two or more previous occasions. Seven out of 23 SMEs used NFTLCs (Interviewees 01, 03, 05, 06, 07, 12, 23) only two of the eleven SMEs in Shaanxi 
used NFTLCs. Four out of seven were medium firms, and three were in the manufacturing sector.

\section{Understanding of the $L C L$}

Most interviewees had a general understanding of the LCL. Only two of the respondents (Interviewees 13 and 22 from small and micro service firms respectively) claimed that they had little or no knowledge of the LCL. 17 respondents expressed various levels of dissatisfaction with the LCL. When questioned about how positively they viewed the LCL they responded using phrases such as: "heavy burden", "increased labour costs", "overprotection", "unfair", "absurd", "unreasonable", and "employment risk increases". For example:

"I am disgusted by the law... Our family also run an exporting trade business which used to have three manufacturing shops. Two of them have closed...We can't guarantee to deliver products on time due to labour shortage and high labour costs... We lost a labour dispute even though we believe our actions were justified...the law always protect workers' interests over employers'. The LCL is really absurd..." (Interview 19, owner, Education, medium size firm).

Contrasting views relating to the introduction of NFTLCs were found. 15 participants expressed general opposition to it while four expressed general support for it. The rest either held neutral attitudes or had little knowledge about it. The contrasting responses were not related to their size or sector. The specific concerns expressed by respondents about aspects of NFTLCs involved issues at both the individual and organisational levels. For example, one group of respondents (Interviewees 02, 04, 10, 11, 14, 17, 20 and 24) indicated that the additional employment security associated with NFTLCs was leading to undesirable working attitudes and encouraging negative attitudes and behaviours at the individual level such as a perfunctory attitude, loss of working enthusiasm and initiative, increased absenteeism, and decreased productivity and commitment. At the organisational level, some respondents (Interviewees 01, 03, 05, 08, 10, 12, 14, 17, 19 and 21) also expressed the view that NFTLCs undermine the flexibility of labour, reduce opportunities to take in "fresh blood" with new ideas, discourage innovation, and decrease profitability. Indicatively,

“...With a non-fixed term contract their mind-set switches from working mode to retirement mode...” (Interviewee 10, HR manager, Photovoltaic manufacturing, medium size firm). 
In contrast, Interviewees $07,15,16$ and 18 expressed the view that the benefits of NFTLCs outweigh their possible deficiencies and highlighted that NFTLCs have an important role to play in enhancing employees' job security and motivation, and strengthening employees' emotional attachment with organisations by promoting loyalty and a sense of belonging. For example, in the words of one respondent:

"I think the introduction of NFTLCs is an improvement...I believe an employee who has been working over ten years for a firm is supposed to be an expert in his/her area. Such an expert needs to be treated as a valuable resource and retained. I don't see any harm of NFTLCs to the firm... " (Interviewee 18, HR and vice general manager, Textile wholesale and retailing, small size firm).

\section{Changes in employment and HRM practices in SMEs}

Table 1 shows the varied practices that were associated employment and HRM strategies.

[Take in Table 1 here]

As indicated in Table 1, for the purpose of lowering labour costs and avoiding labour disputes, some of the respondents (for example, Interviewees 05, 06, 07, 08, 09, 10, 11, 15, 16,23 , seven of whom were from medium manufacturing firms) revealed that, since the enactment of the LCL, they had increased their use of sub-contracted labour and also tended to offer more internships especially in labour-intensive sectors and for low-skill positions. The respondents were from For example:

“...We have connections with local labour dispatch agencies and technical schools. Many shop floor workers are recruited from these sources...If we need more people during the peak period, they are the first choices... They (agencies and schools) are relatively flexible and cost-effective in meeting our labour demand" (Interviewee 09, HR/ vice general manager, Precise instrument accessories manufacturing, medium size firm).

Further, the interview data reveal that an emergent practice in this sample of SMEs was to negotiate with and persuade employees to voluntarily request termination of their employment. The interview data reveal that this practice of attempting to persuade employees to request voluntary termination of their employment has been adopted by SMEs of different sizes in various sectors because, in cases where employees resign, the employers are not obligated to pay severance under the LCL. In the words of one of the respondents: 
"...If we want someone to leave, we have two options: paying him severance or not depending on how we communicate with him/her...In most cases, we would persuade him/her to voluntarily resign for the sake of decency. Then we don't need to pay and he/she can leave a decent impression on other workers and future employers" (Interviewee 01, owner, Medical devices wholesale and retailing, small size firm).

In relation to HRM practices, some respondents (for example, Interviewees 04, 19) were engaged in HR planning involving downsizing while some explicitly claimed that they were more cautious on staffing and hiring decisions and used recruitment methods involving acquaintance referrals, labour dispatch agencies and vocational schools (for example, Interviewees 07, 08, 09, 19, all in medium size firms). As indicated in Table 1, the interview data also revealed the practice of inviting lawyers to provide training about the provisions of the LCL to HR personnel and senior managers, especially in the medium-sized firms. Given the cost of training activities, formal training and development agreements between employers and employees were operationalised to minimise post-training voluntary turnover. For example, one respondent stated:

"Due to the increased labour cost, I had to downsize... We are really careful about recruitment... We now use more reliable recruitment sources, such as referral by acquaintance..." (Interviewee 19, owner, Education, medium size firm)

As a corollary of the LCL, the interview data reveal that reward management practices in SMEs have become increasingly formalised in three different ways. First, compensation policies and procedures were specified in written forms with such documents present in 20 out of 23 SMEs albeit with varying degrees of comprehensiveness. The three SMEs which did not have written policies and procedures were micro and small firms in the service sector. Second, the interview data highlight that the benefits of social insurance, the ratio of firms' contribution to social insurance, and the coverage of employees under welfare programmes have all been extended in response to the enactment of the LCL. Levels of severance pay were also increased. Work performance was measured in over 90 per cent of the SMEs with respondents confirming that they used specified criteria on assessing performance, the existence of links between rewards and performance, and the practice of keeping records of performance evaluation results for both reward and discipline purposes. Two small firms in the service sector reported that they did not link work performance to incentives. The majority of respondents indicated that rules and disciplinary procedures at work were also 
formulated in a rigorous, formally documented and accessible manner. Indicative quotes obtained from the respondents included:

"We participate in welfare schemes by providing five types of insurance and a housing fund, though I disagree with the coercive nature of such participation..." (Interviewee 03, owner, Real estate, small size firm).

“...We have modified working rules and disciplinary procedures to be stricter. In practice, we don't necessarily follow them strictly. But it is always better to play safe..." (Interviewee 24, owner, Daily chemicals wholesale and retailing, medium size firm).

\section{Discussion}

This study explores perceptions of the LCL and its influence on employment relations and HRM practices in the privately-owned SME sector in mainland China from an employers' perspective. The following discussion of the findings is structured using the two research questions presented above.

\section{How do SME owners and HR managers perceive employment law?}

In this study, we found that, while the respondents expressed their awareness of various provisions of the LCL, most of them objected to the obligations it placed on them. The main stated considerations behind such views related to increased labour costs, increased employment risks and perceptions of unfair stipulations about the protection of employees' rights and interests. Respondents also suggested that there was a lack of reality on the part of policymakers about the difficulties faced by privately-owned SMEs in matters relating to competitiveness in the market, accessing financial resources, and attracting talent. As such, the findings are relatively consistent with the findings of Tang and Tang (2012) and Chan (2012) and the analysis of Gallagher et al. (2015) which indicated a general agreement among managers that the LCL had led to increased labour costs. Further, SME employers' general distaste for LCL may be explained by the nature of employment relations in SMEs. That is, the characteristics of informality and flexibility in this sector are likely to be challenged by the increasing levels of formality imposed by regulations (Mallett et al., 2019).

The findings reveal that all the SMEs except one micro firm stated that they were complying with the legal requirement of concluding written labour contracts. Given that the establishment of formal employment relationships is at the core of the LCL, it provides an indication that the SME sector has moved towards formalising employment relations. Theoretically, the findings offer support for the coercive mechanism of institutional theory 
(Paauwe and Boselie, 2003), that is, although SME owners used to take advantage of informal relationships for maintaining labour flexibility and minimising labour costs, they are now making more use of formal employment contracts as a means of obtaining legitimacy under the regulatory pressures of the LCL.

The findings also reveal that one-year and three-year contracts are the most common types of fixed-term contracts used by the sample of SMEs involved with this study. In relation to the size of the SME, our findings suggest that micro and small SMEs in the service sector were most likely to adopt consistent contract length practices whereas the medium size firms in the manufacturing sector were more likely to use fixed-term contracts of various lengths. This finding tends to support the essence of Huselid and Becker's general assertion (2011) that valuable jobs should be managed differently from those less value-added roles. Thus, the data provides some evidence that, despite the relative informality of aspects of HRM in the SME sector in China, employers are perhaps intuitively recognising: “... that some jobs are more valuable (strategic) than others, and they should be managed accordingly" (ibid: 424).

Although fixed term contracts remain relatively short, particularly for employees in relatively low-grade positions, the findings also reveal that some SMEs are willing to agree to fixed-term contracts of up to five years especially for key professional employees in technical and managerial positions. Such a strategy indicates an attempt by the owners of SMEs to maintain a balance between labour flexibility and the retention of key employees. This stratified strategy requires owner-managers to evaluate, negotiate and balance how much discretion to maintain and how much flexibility to give up (Mallett et al., 2019). Interestingly, the respondents also revealed that some workers preferred short-term contracts to improve their mobility and bargaining power in pay negotiations; as such, this phenomenon is likely to be related to skills shortages in particular sectors in higher labour mobility regions in China. Thus, it can be seen that factors such as the preferences of employee, the sector, the size of the SME, and the labour market are likely to influence the extent and results of adaptation. More importantly, specific adaptation results could lead to re-evaluating and re-negotiating in dynamic environments when, for example, employees request shorter contracts in times of labour shortage.

The tendency for SMEs to adopt differentiated employment and formalised HRM practices as they grow in size is well documented (Kim and Gao, 2010). Our findings contribute to this literature by highlighting that this tendency may, in part, be explained by the increasingly complex types of roles that can be associated with the success and growth of an SME. As such, it is possible to speculate that that the introduction of formalised HRM 
practices in areas such as reward and employment contracts may be attributable to the value which employers place on role incumbents as well as to the need for structure and order in employment matters. Here, we note that in western literature on SMEs, the importance of psychological variables, such as employers' levels of emotional intelligence, has been recognised when considering how talent retention strategies and decisions are made by owners and HR staff (Cuéllar-Molina et al,. 2019). In relation to the context of SMEs in China, studies focusing on individual variables are notable by their scarcity even though, as the findings of our study demonstrate, employers and HR staff in this context are also making value-laden judgements about how to retain talent within their firms.

In addition to general compliance with the LCL such as the requirement for employers to issue written contracts, this study also explored issues relating to NFTLCs. On the basis of the interview data, we surmise that, in overall terms, general distaste of NFTLCs was found among the studied SMEs with no obvious variations in practices found in relation to the size or sector of the SMEs in our sample. At least a proportion of SMEs in China are reluctant to engage fully with NFTLCs. Arguably, this reluctance may be attributable to a number of factors. First, the long-term orientation of NFTLCs could be perceived as being incompatible with SMEs' relatively short life-span. Second, the introduction of NFTLCs may be perceived by owners as a source of difficulty in employment termination decisions because it reduces employers' discretion and autonomy. Third, given the reported high rates of turnover in SMEs, there may be relatively few employees who meet the criteria of NFTLCs especially in smaller firms. Fourth, it could be an employee's personal preference to sign a fixed-term contract rather than move to an open-ended contract.

The findings further revealed the commonly held perception that NFTLCs exerted an adverse impact on both individual and organisational outcomes. Correspondingly, while the majority of the respondents expressed concerns about the creation of negative work behaviours among employees who have been offered an NFTLC, very few of the respondents recognised the potential for NFTLCs to exert a positive impact on attitudes and behaviours in the workplace by creating, for example, a stronger sense of belonging, enhanced emotional bonding, and employee commitment. This finding emphasises the need for policymakers and authorities at both national and local levels, to provide SME owners with information about the rationale behind and potential benefits of NFTLCs.

\section{How are employment and HRM practices in SMEs being influenced by the LCL?}


The findings of the study reveal that, at times, the respondents adopt a somewhat covert approach to terminating employment relationships to avoid costly severance payments. In such cases, the termination is portrayed by both parties as voluntary resignation rather than as termination of employment. This finding provides further evidence that there may be an increasing tendency for termination of employment in this sector to be undertaken in a highly cautious and arguably devious manner compared to the pre-2008 situation (Wang et al., 2009). The findings also support findings of previous studies by highlighting that labour subcontracting and student internships are increasingly used within this sector, especially in medium size manufacturing firms in Jiangsu where there is high labour mobility and a shortage of low skilled workers, in a further attempt to avoid making the severance payments required under the legal requirements of NFTLCs (Friedman and Kuruvilla, 2015; Gallagher et al., 2015). In a similar vein, our findings identify the increased use of dispatch (or agency) labour which would undermine the LCL's goals of protecting employees. Thus, despite relatively recent amendments to the LCL which place restrictions of the types of posts and the percentage of the number of employees that can be filled by dispatch labour (PRC, 2014), the findings provide further evidence of the use of dispatch labour though further research is needed to explore whether this is also attributable to factors such as the links between local governments and labour service agencies (Friedman and Kuruvilla, 2015; Gallagher et al., 2015).

On the basis of the interview data, this study has also found that reward management practices associated with wages and social insurance have been increasingly formalised as a result of the enactment of the LCL. This finding concurs with the results of related studies (Cui et al., 2013; Gallagher et al., 2015; Liang et al., 2012). Thus, despite some remaining informality, the present evidence suggest that the compensation practices in SMEs are likely to become increasingly formalised particularly given the need for social insurance participation within the context of the aging population in China. Moreover, the increasing level of formality relating to reward management practices which has been promoted by the LCL may potentially contribute to higher employee commitment and lower turnover intention. Notably, Li et al (2019) report that reward management practices represent the second strongest predictor of employee outcomes. On the basis of our findings, we conclude that the LCL may have a role to play in addressing issues surrounding labour shortage and high turnover rates in the SME sector in China (Cooke, 2012).

Lastly, the findings reveal notable developments relating to the formal documentation of policies, procedures and rules relating to employment practices in SMEs in China. For 
example, the interview data highlight that: T\&D agreements, working rules and disciplinary procedures were being rigorously documented; performance assessment criteria were being established and linked to rewards; and related records were being kept in a systematic manner. It is emphasised that HR documentation is both a component of lawful HR practices in many other countries (Hashim et al., 2016) and also a sign of professionalism when seeking to attract and retain employees and when resolving employment problems and disputes (Michiels, 2017; Newman and Abdullah, 2014). In this study, although these initiatives were taken by employers for their own benefit, they also had the corollary of enhancing employment protection for employees (Sheehan, 2014). These observations do suggest a potential trend in the management style within the SME sector in China, that is, from a discretionary informal style to a more prescriptive and formalised style of management which is being encouraged by the LCL (Liang et al., 2012). We recognise that advocates of "small is beautiful' may question whether there is a genuine business need for employers to formalise HR practices in the SME sector in China. The reality is, however, that in China, as in many other national contexts, employment relationships and their associated HR practices are increasingly regulated by employment law (Hashim et al., 2016; Pittino et al., 2016).

In comparison with previous literature which found various levels informality in this sector (Bai et al., 2017; Cooke, 2012; Cunningham, 2010; Harney and Alkhalaf, 2020; Kim and Gao, 2010; Paul et al., 2017; Richbell et al. 2010; Singh and Vohra, 2009), our findings indicate that, under the pressure of the LCL, SME owners have been overtly formalising their HR practices while, at the same time, developing covert and experimental approaches for maintaining flexibility of employment. This finding resonates with Kitching and Marlow's (2013: 37) conclusions that: “(small firms') managers must navigate a path between rationality and intuition, formality and informality..." and that this hybrid of formality and informality embedded in their practices is constantly changing by balancing the internal and external dynamics (ibid, 2013).

Overall, the findings of this study provide insights into how SME employers perceive the new regulations contained within the LCL and the influence of these regulations on employment practices. The findings also provide insights into employers' responses to regulatory interventions in the SME sector in China in the following ways. First, the findings provide evidence that SME employers do engage with the four key processes identified by Mallett et al. (2019). Importantly, the authors present their framework as "a collection of processes" rather than as processes which occur in a one-directional sequential order (ibid, 2019: 310). Our findings provide support for this view. Thus, the processes identified in our 
study were not followed sequentially in one direction from perception to adaption. For example, our findings reveal that the adoption process may have a reverse effect, that is, the adaption results may reshape how employers negotiate with, strategise and perceive the regulations by reconsidering diverse and constantly changing contingencies. Mallett et al. (2019: 310) also conclude that the four regulatory adoption processes are interconnected, though: "The extent of such interconnectedness is not revealed in detail by our synthesis of existing studies because it has not received significant attention, but emerging insights from this literature review are suggestive of the importance of this perspective and indicate a future research agenda." As discussed above, our study draws attention to both the existence and nature of this interconnectedness; the findings highlight that the four regulatory adoption processes are likely to influence each other, and as such, regulatory adoption involves continuously interactive relationships among the four processes.

Second, the findings offer partial support for the coercive mechanism of institutional theory (Paauwe and Boselie, 2003) as evidenced by employers' compliance with the requirement to issue concluding written contracts and also employers' reluctance to be engaged fully with NFTLCs. Moreover, in our research context, new forms of strategies and practices are emerging to compensate for the perceived compliance costs of the LCL. These emerging practices involve, for example, voluntary resignation, increasing use of labour dispatch, and student internships. On the basis of these findings, it is reasonable to question whether institutional forces tend to shape SME owners' behaviours and choices in a homogenous way. That is, SMEs are regulated by the core requirements of regulations but the findings indicate that employers in this sector are adopting a variety of different practices in their quest for the flexibility required in their sector (Mallett et al., 2019).

\section{Conclusions}

This research explores how owners and HR managers in privately-owned SMEs in China understand the LCL, and its influence on employment and HRM practices. The study contributes to existing knowledge by providing insights into employers' perceptions of employment issues and expanding knowledge of the influence of the LCL on HRM in the SME sector. The results indicate that the SME owners and HR managers we interviewed had a general understanding of the LCL but many were unhappy with the requirements which it placed upon them. Hence, while we found that, while overall compliance with issues such as the provision of written contracts was taking place, adherence to the requirements of NFTLCs remained limited. The conclusion we draw is that SMEs in China are moving towards more 
formal employment relations but compliance with NFTLC legislation within this sector remains problematic. In effect, SMEs have been formalising their management practices while retaining a degree of informality, and perhaps developing new or amending existing practices to counteract the perceived negative impact of the LCL in relation to issues such as open contracts and severance pay. Such a complex co-existence of informalities and formalities is likely to continue and develop unevenly in the SME sector.

The findings of the current study have both theoretical and empirical implications. First, in providing mixed empirical evidence of the coercive mechanism of institutional theory, they support the partial transferability of this theory into the studied context. On the one hand, SMEs owners and HR managers recognised the need to comply with core requirements of the LCL despite the pervasive objections to it which exist within the sector. On the other hand, compliance with NFTLCs appears to be limited in the SME sector. These mixed findings serve as a note of caution should the coercive mechanism be used predominantly to explain the regulatory adoptive behaviours and practices of SMEs, even within a relatively authoritarian context such as China. Given the nature of SMEs (Ram et al., 2019), new strategies were observed in this study to maintain discretion and flexibility involving, for example, voluntary resignation, the increasing use of labour dispatch, and student internships. On the basis of our findings, we conclude that regulatory responses in the SME sector in China are informed by both the pressures of institutional expectations and the decisions of human actors such as employers.

Second, the findings relating to SME employers' perceptions of the LCL and the adopted regulatory practices provide support for the view that the four key processes of regulatory adoptive responses, identified by Mallett et al. (2019), should not be seen as discrete entities but rather as sub-processes which integrate and embed with each other as a continuously interactive process. This finding is likely to be of interest to researchers who are seeking to apply Mallet et al.'s framework in order to gain an understanding of the adoption of regulatory practices in various contexts.

Third, given the reported high turnover rates and widespread labour shortages in this sector (Friedman and Kuruvilla, 2015), SMEs could make better use of the opportunity afforded by the LCL to enhance their management capability and improve their HRM systems in areas such as recruitment, measurable performance assessment and its links with rewards, and the use of systematic documentation. These initiatives have been highlighted by the findings of this study which identify specific areas in which SMEs have the potential to move from a more reactionary and subjective style of management to a more formalised style 
of management which may accentuate some of the positive behaviours derived from consistency, standardisation and equality. Further, by placing a particular focus on NFTLCs and further analysing support and opposition to them from a managerial perspective, the study has identified aspects of NFTLCs which can be drawn upon to develop motivation and retention strategies for SMEs while identifying other aspects which need to be revisited by policymakers when reviewing the impact of the LCL within the SME sector.

Fourth, the study is particular useful for policymakers, local governments and labour authorities because, unlike most extant research, this study reports the views of owners and HR managers in the SME sector towards the LCL. Their perceptions largely determine how their firms respond to employment regulations (Mayson and Barrett, 2017). Chung (2015) has succinctly emphasised that, when the interests of local government, labour intermediaries and employees are convergent, compliance is greater. Similarly, when writing about the "Employer-Employee-Government relationship" in China, Guo et al. (2016: 2157) emphasise that: "The government should examine its policy enforcement tools and their effects, adjusting, where possible, relevant regulations to better accommodate the needs and capacities of enterprises". We trust that this study has helped to create a better understanding of SME owners' and HR managers' perceptions of the LCL and that these insights will help policymakers and local governments to consider how to ease prevailing dissatisfaction and concerns among SME owners, in order to offset the potentially adverse impacts of the LCL. The findings also highlight the need for further research into key psychological variables which are associated with the HR-related decision-making of owners and HR staff in the SME sector in China.

Finally, several limitations of the study are highlighted. First, the analysis is based on cross-sectional data. A future longitudinal study is encouraged to compare the trends and changes which have been brought about by the LCL. For example, the interview findings indicate that the use of labour sub-contracting and student labour is growing. It would be enlightening to investigate the impact of legislation on these phenomena over time especially given that new regulations on dispatch labour were enacted in 2014. Second, a qualitative approach has been adopted to gather and interpret interview data and, as such, the findings should not be portrayed as representative of the SME sector across China. Third, although this study addresses the under-explored SME employers' perspectives of the LCL, it is acknowledged that employees' perspectives are likely to provide another fruitful avenue of enquiry. 


\section{References}

Bai, Y., Yuan, J. and Pan, J. (2017), "Why SMEs in emerging economies are reluctant to provide employee training: evidence from China", International Small Business Journal, Vol. 35 No. 6, pp.751-766.

Chambliss, D.F. and Schutt, R.K. (2010), Making Sense of the Social World, $3^{\text {rd }}$ Edition, Sage, Thousand Oaks.

Chan, K. (2012), “The global financial crisis and labor law in China”, Chinese Economy, Vol. 45 No. 3, pp. 24-41.

Cheng, Z., Smyth, R. and Guo, F. (2015), “The impact of China's new Labour Contract Law on socioeconomic outcomes for migrant and urban workers", Human Relations, Vol. 68 No. 3, pp. 329-352.

Chung, S. (2015), "Explaining compliance: A multi-actor framework for understanding labour law compliance in China”, Human Relations, Vol. 68 No. 2, pp. 237-260.

Cooke, F.L. (2011), "Labour market regulations and informal employment in China: to what extent are workers protected?", Journal of Chinese Human Resources Management, Vol. 2 No. 2, pp. 100-116.

Cooke, F.L. (2012), Human Resource Management in China: New Trends and Practices, Routledge, Abingdon.

Cooke, F.L. and Saini, D.S. (2012), "Managing diversity in Chinese and Indian organizations: a qualitative study", Journal of Chinese Human Resources Management, Vol. 3 No. 1, pp. 16-32.

Cuéllar-Molina, D., García-Cabrera, A.M. and de la Cruz Déniz-Déniz, M. (2019), "Emotional intelligence of the HR decision-maker and high-performance HR practices in SMEs”, European Journal of Management and Business Economics, Vol. 28 No. 1, pp. 52-89.

Cui, F., Ge, Y. and Jing, F. (2013), "The effects of the Labor Contract Law on the Chinese labor market", Journal of Empirical Legal Studies, Vol. 10 No. 3, pp. 462-483.

Cunningham, L.X. (2010), "Managing human resources in SMEs in a transition economy: evidence from China", The International Journal of Human Resource Management, Vol. 21 No. 12, pp. 2120-2141.

Edwards, P., Ram, M., Sen Gupta, S. and Tsai, C. (2006), "The structuring of working relationships in small firms: towards a formal framework", Organization, Vol. 13 No. 5, pp. 701-724. 
Freeman, R.B. and Li, X. (2013), "How does China's new labor contract law affect floating workers?", NBER working paper series No.19254, National Bureau of Economic Research, Cambridge, July.

Friedman, E. and Kuruvilla, S. (2015), "Experimentation and decentralization in China's labor relations", Human Relations, Vol. 68 No. 2, pp. 181-195.

Frenkel, S.J. and Yu, C. (2015), “Chinese migrants' work experience and city identification: challenging the underclass thesis", Human Relations, Vol. 68 No. 2, pp. 261-285.

Gallagher, M., Giles, J., Park, A. and Wang, M. (2015), “China's 2008 Labor Contract Law: implementation and implications for China's workers", Human Relations, Vol. 68 No.2, pp. 197-235.

Gao, Q., Yang, S. and Li, S. (2017), "Social insurance for migrant workers in China: impact of the 2008 Labour Contract Law”, Economic and Political Studies, Vol. 5 No. 3, pp. 285304.

Grbich, C. (2013), Qualitative Data Analysis: An Introduction, $2^{\text {nd }}$ Edition, Sage, London.

Guo, Y., Tian, M., Han, K., Johnson, K. and Zhao, L. (2016), "What determines pension insurance participation in China? Triangulation and the intertwined relationship among employers, employees and the government", The International Journal of Human Resource Management, Vol. 27 No. 18, pp. 2142-2160.

Harney, B. and Alkhalaf, H. (2020), "A quarter-century review of HRM in small and medium-sized enterprises: capturing what we know, exploring where we need to go", Human Resource Management, https://doi.org/10.1002/hrm.22010.

Hashim, J., Ismail, Y. and Hassan, A. (2016), "Formality of HRM practices matters to employees satisfaction and commitment", Journal of Human Resources Management and Labor Studies, Vol. 4 No. 1, pp.47-64.

Huselid, M.A. and Becker, B.E. (2011), "Bridging micro and macro domains: workforce differentiation and strategic human resource management", Journal of Management, Vol. 37 No. 2, pp. 421-428.

Kim, Y. and Gao, F.Y. (2010). "An empirical study of human resource management practices in family firms in China", The International Journal of Human Resource Management, Vol.21 No. 12, pp. 2095-2119.

Kitching, J. and Marlow, S. (2013), "HR practices and small firm growth: balancing informality and formality", in Saridakis, G. and Cooper, C.L. (Eds.), How Can HR Drive Growth?, Edward Elgar, Cheltenham, UK, pp. 26-45. 
Kopnina, H. (2005), "Family matters? Recruitment methods and cultural boundaries in Singapore Chinese small and medium enterprises", Asia Pacific Business Review, Vol. 11 No 4, pp. 483-499.

Lan, T., Pickles, J. and Zhu, S. (2015), "State regulation, economic reform and worker rights: the contingent effects of China's Labour Contract Law", Journal of Contemporary Asia, Vol. 45 No. 2, pp. 266-293.

Li, S., Rees, C.J. and Branine, M. (2019), “Employees' perceptions of human resource management practices and employee outcomes: empirical evidence from the small and medium-sized enterprises sector in mainland China”, Employee Relations, Vol. 41 No 6, pp. 1419-1433.

Li, N., Toppinen, A. and Lantta, M. (2016), "Managerial perceptions of SMEs in the wood industry supply chain on corporate responsibility and competitive advantage: evidence from China and Finland. Journal of Small Business Management, Vol. 54 No.1, pp. 162186.

Liang, X., Marler, J.H. and Cui, Z. (2012), "Strategic human resource management in China: east meets west", Academy of Management Perspectives, Vol. 26 No. 2, pp. 55-70.

Malesky, E. and Taussig, M. (2017), "The danger of not listening to firms: government responsiveness and the goal of regulatory compliance", Academy of Management Journal, Vol. 60 No. 5, pp. $1741-1770$.

Mallett, O., Wapshott, R. and Vorley, T. (2019), "How do regulations affect SMEs? A review of the qualitative evidence and a research agenda", International Journal of Management Reviews, Vol. 21 No. 3, pp. 294-316.

Mayson, S. and Barrett, R. (2017), “A new argument using embeddedness and sensemaking to explain small firms' responses to employment regulation", Human Resource Management Journal, Vol. 27 No. 1, pp. 189-202.

Michiels, A. (2017), "Formal compensation practices in family SMEs", Journal of Small Business and Enterprise Development, Vol. 24 No. 1, pp. 88-104.

Newman, A. and Sheikh, A.Z. (2014), "Determinants of best HR practices in Chinese SMEs", Journal of Small Business and Enterprise Development, Vol. 21 No. 3, pp. 414430.

Paauwe, J. and Boselie, P. (2003), "Challenging 'strategic HRM' and the relevance of the institutional setting", Human Resource Management Journal, Vol. 13 No. 3, pp. 56-70.

Paul, J., Parthasarathy, S. and Gupta, P. (2017), "Exporting challenges of SMEs: a review and future research agenda", Journal of World Business, Vol. 52 No. 3, pp.327-342. 
Pittino, D., Visintin, F., Lenger, T. and Sternad, D. (2016), “Are high performance work practices really necessary in family SMEs? An analysis of the impact on employee retention", Journal of Family Business Strategy, Vol. 7 No. 2, pp.75-89.

PRC (2011), "Provisions on the standards for SMEs", People's Republic of China, available at: www.gov.cn/zwgk/2011-07/04/content_1898747.htm (accessed 20 December 2019).

PRC (2013), “The Labour Contract Law of the People's Republic of China", People's Republic of China, available at: http://www.npc.gov.cn/wxzl/gongbao/201304/15/content_1811058.htm (accessed 5 December 2019).

PRC (2014), "Provisional Regulations on Dispatch Labour", People's Republic of China, available at: http://www.mohrss.gov.cn/gkml/xxgk/201401/t20140126_123297.htm (accessed 4 January 2020).

Pringle, T. and Meng, Q. (2018), “Taming labor: workers' struggles, workplace unionism, and collective bargaining on a Chinese waterfront", ILR Review, Vol. 71 No. 5, pp. 10531077.

Ram, M., Edwards, P., Meardi, G., Jones, T. and Doldor, S. (2019), "The roots of informal responses to regulatory change: non-compliant small firms and the national living wage", British Journal of Management, 00, pp. 1-16.

Richbell, S., Szerb, L. and Vitai, Z. (2010), "HRM in the Hungarian SME sector", Employee Relations, Vol. 32 No. 3, pp. 262-280.

Sheehan, M. (2014), "Human resource management and performance: evidence from small and medium-sized firms", International Small Business Journal, Vol. 32 No. 5, pp.545570.

Sheldon, P. and Sanders, K. (2016), "Contextualising HRM in China: differences within the country", The International Journal of Human Resource Management, Vol. 27 No. 18, pp. 2017-2033.

Shen, J. (2010), "Employees' satisfaction with HRM in Chinese privately-owned enterprises”, Asia Pacific Business Review, Vol. 16 No. 3, pp. 339-354.

Singh, M. and Vohra, N. (2009), "Level of formalisation of human resource management in small and medium enterprises in India", The Journal of Entrepreneurship, Vol. 18 No. 1, pp. 95-116.

Smith, C. and Chan, J. (2015), "Working for two bosses: student interns as constrained labour in China", Human Relations, Vol. 68 No. 2, pp. 305-326. 
Tang, Z. and Tang, J. (2012), "Entrepreneurial orientation and SME performance in China's changing environment: the moderating effects of strategies", Asia Pacific Journal of Management, Vol. 29 No. 2, pp. 409-431.

Wang, H., Appelbaum, R.P., Degiuli, F. and Lichtenstein, N. (2009), “China's New Labour Contract Law: Is China moving towards increased power for workers?", Third World Quarterly, Vol. 30 No. 3, pp. 485-501.

Wang, F., Gan, B., Cheng, Y., Peng, L., Feng, J., Yang, L. and Xi, Y. (2019), “China's employment contract law: Does it deliver employment security?", The Economic and Labour Relations Review, Vol. 30 No. 1, pp. 99-119.

Xiu, L., Liang, X., Chen, Z. and Xu, W. (2017), "Strategic flexibility, innovative HR practices, and firm performance: a moderated mediation model", Personnel Review, Vol. 46 No. 7, pp. 1335-1357.

Yang, D. (2020), "Why don't they complain? The social determinants of Chinese migrant workers' grievance behaviors", ILR Review, Vol. 73 No. 2, pp. 366-392.

Zhu, Q. and Sarkis, J. (2007), “The moderating effects of institutional pressures on emergent green supply chain practices and performance", International Journal of Production Research, Vol. 45 No. 18-19, pp. 4333-4355. 
Table 1. Summary of strategies used in employment and HRM practices in SMEs.

\begin{tabular}{ll}
\hline & Adopted strategies \\
\hline Employment & $\begin{array}{l}\text { Encouraging resignation requests to be made by employees rather } \\
\text { than terminating their employment contracts. } \\
\text { Amending labour contracts (for example, by tightening the } \\
\text { conditions of termination, highlighting conduct requirements, stating } \\
\text { disciplinary measures, adding specific terms relating to NFTLCs). }\end{array}$ \\
& Making more use of sub-contracted labour and/or student labour. \\
& Engaging in downsizing activities. \\
HR planning & Using more varied recruitment sources like referrals. \\
Staffing & Working more extensively with labour dispatch agencies, vocational \\
& schools and on-campus job centres. \\
Taking more caution when making selecting and hiring decisions. & Providing training about the LCL to HR people and senior managers. \\
Training and & Being more careful when selecting employees for T\&D activities \\
development & with reference to their contracts of employment. \\
(T\&D) & Rigorously drafting T\&D agreements to recover costs in turnover \\
situations. & Formalising and documenting compensation practices. \\
Reward & Expanding the coverage of social insurance. \\
management & Increasing levels of severance pay. \\
Performance & Specifying performance assessment criteria. \\
management & Formally linking performance with rewards. \\
Documenting performance appraisal records. & Rigorously formulating and formally documenting terms and \\
procedures & conditions of employment. \\
\hline &
\end{tabular}




1
2
3
4
5
6
7
7
8
9
9
10
11
12
13
14
15
16
17
18
19
19
20
21
22
23
23
24
25
26
27
27
28
29
30
31
3

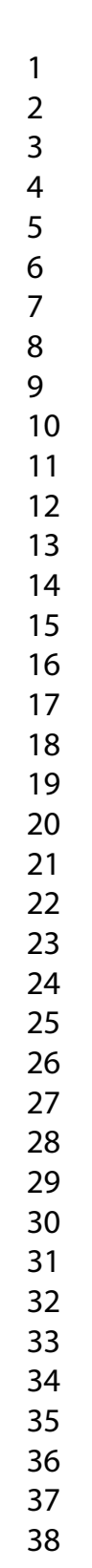

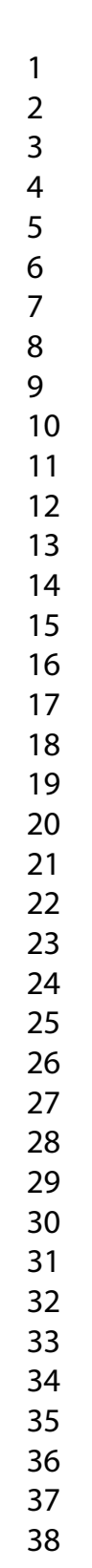

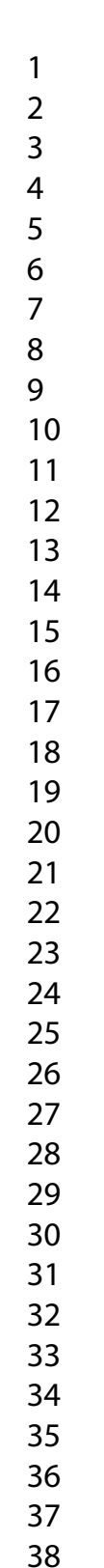

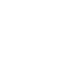

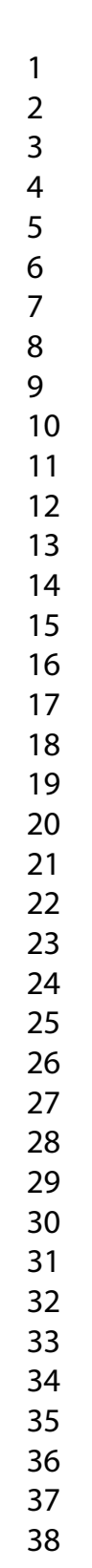
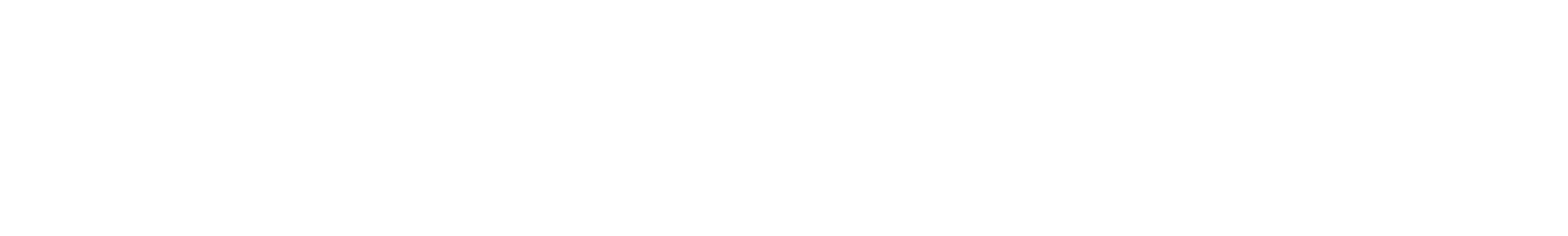

(2)

.

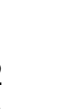

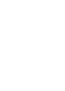

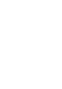

42
43
44
45
46
47
48
49
50
51
52
53
54
55
56
57
58
59
60

.

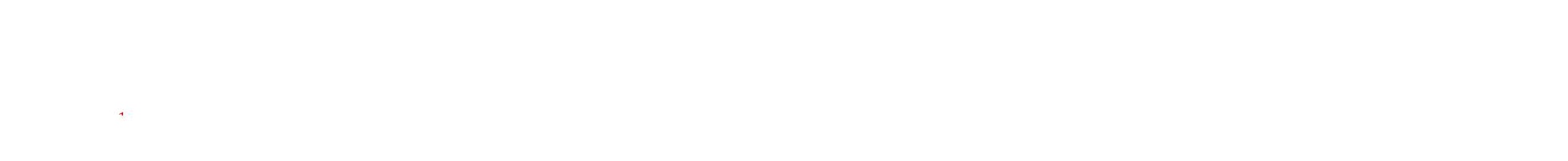


